Theoretical Articles

\title{
Political Motivation: A Referent Evaluation Mathematical Model
}

\author{
Francesco Rigoli ${ }^{\mathrm{a}}$ \\ [a] Department of Psychology, City University of London, London, United Kingdom.
}

Journal of Social and Political Psychology, 2021, Vol. 9(1), 8-23, https://doi.org/10.5964/jspp.5539

Received: 2020-05-04 • Accepted: 2020-09-28 • Published (VoR): 2021-02-19

Handling Editor: J. Christopher Cohrs, Philipps University Marburg, Marburg, Germany

Corresponding Author: Francesco Rigoli, Department of Psychology, City University of London, Northampton Square, London, UK EC1V 0HB. E-mail: francesco.rigoli@city.ac.uk

\begin{abstract}
Mathematical modelling is popular in cognitive psychology because it enables clear and formal descriptions of the processes at play; yet, this approach has rarely been applied to political psychology. Here we adopt mathematical modelling to develop a theory of political motivation, which is a central concept in political psychology. The theory assumes that, in certain contexts, individuals entertain a set of representations of society, for example of the past, present and future (but also of fictive societies such as utopias). To each representation of society, an incentive value is attached which is not absolute, but (following theories of motivation in cognitive psychology) reference-dependent; namely, dependent on the context, corresponding to the whole set of representations of society. In turn, the model proposes that these subjective values determine two central aspects: a motivation for performing an appropriate political action and the ensuing political mood. We discuss the model with respect to theoretical and empirical research (and we examine Marx and Engel's communist manifesto as an example of the latter). In short, we offer a new mathematical perspective on political motivation which emphasises the role of multiple representations of society in determining political motivation and the ensuing political mood.
\end{abstract}

\section{Keywords}

political motivation, political mood, referent dependent, context effect, mathematical modelling, political action, relative deprivation

In political psychology, a fundamental question concerns the nature of political motivation. In other words, why are certain people motivated to perform political actions such as voting or protesting, while other people lack such motivation? This question is important in several domains, including social identity theory (Hogg, 2018; Mackie et al., 2000; Mackie \& Smith, 2002; Tajfel, 1981; Tajfel \& Turner, 1979; Turner et al., 1987), relative deprivation theory (Crosby, 1976; Davies, 1962; Folger, 1986; Gurr, 1970; Runciman, 1966; Smith \& Pettigrew, 2015; Stouffer et al., 1949), research on collective action (Davies, 1962; Gurr, 1970; Klandermans \& van Stekelenburg, 2013; Olson, 1965; Van Zomeren et al., 2008), and research on the psychology of morality and justice (Deutsch, 1975; Doris, 2010; Haidt, 2007; Tyler, 2003). Building on insights offered by this literature, the paper proposes a general theory of political motivation that relies on mathematical modelling. Such mathematical outlook is novel in political psychology, yet it can potentially offer important insights and spark new research lines (Fried, 2020; Rollwage et al., 2019; Zmigrod, 2020). This relies on describing key processes underlying a phenomenon using simple mathematical modelling (Fried, 2020; Rollwage et al., 2019; Zmigrod, 2020). Though, by reducing a phenomenon to mathematics, this perspective requires simplifications (examined in the discussion), the advantage is that key processes can be defined formally and clearly, thus facilitating theoretical debate and identification of empirical predictions.

The paper is structured as follows. The next section will describe the model, which is referred to as a Computational model of political motivation (CMPM). Reference effects (which are ubiquitous in cognition; e.g., Helson, 1948; Parducci, 
1965; Kahneman \& Tversky, 1979) will be highlighted as a key feature of the model; these will be examined in the third section. The fourth and fifth sections will consider implications for previous theories and for potential empirical research, respectively. Finally, the paper will conclude with a discussion of the model regarding more general issues.

\section{The Model}

Contemporary mathematical models of motivation (Glimcher \& Fehr, 2013; Newell et al., 2015) are built upon three fundamental assumptions. These assumptions are also the basis for the CMPM and are illustrated here. Shared by virtually all mathematical models of motivation, the first assumption maintains that the brain constantly generates representations of salient states of affair such as being at the cinema, being at work, or being stung by a wasp (Glimcher \& Fehr, 2013; Newell et al., 2015; Schacter et al., 2007; Suddendorf \& Corballis, 2007). Representations can describe previous, current, future, or even fictive, states of affair (Schacter et al., 2007; Suddendorf \& Corballis, 2007). To each representation the brain is assumed to assign an incentive value (mathematically represented by a real number) which is at the root of motivation (Glimcher \& Fehr, 2013; Newell et al., 2015). For example, the brain will assign a positive value to being at the cinema and a negative value to being stung by a wasp. The CMPM extends this idea to the political domain by postulating that, in some circumstances, the brain not only generates representations about personal states of affair, but also about society (a similar perspective has been advocated by research on group-based self-regulation and on utopia; Fernando et al., 2018; Sassenberg \& Woltin, 2008). In other words, the CMPM assumes that the brain entertains representations describing different forms of society, for example describing a society in the past, present, and future, or describing fictive societies (i.e., such as in utopian representations). These not only describe how history is conceived (i.e., how society has changed and may change in the future), but they may include virtual realities, for example describing how society could have developed in different conditions, or describing societies with no link to history (as in utopias). In keeping with mathematical models of motivation (Glimcher \& Fehr, 2013; Newell et al., 2015), the CMPM assumes that an incentive value (represented mathematically by a real number) is attached to each of these representations of society. Such incentive value can integrate both costs and benefits associated with a society, and it can integrate both self-interest aspects (e.g., what is good for me) as well as ethical aspects (e.g., what is just).

The second assumption (influential in mathematical models of motivation; e.g., Helson, 1948; Kahneman \& Tversky, 1979; Louie et al., 2013; Louie \& Glimcher, 2017; Parducci, 1965; Rigoli, 2019; Stewart et al., 2006) is that the incentive value attached to a representation is not absolute but reference-dependent. As an illustrative example of reference-dependency in evaluation processes outside the political domain, consider an individual who, right before closing a deal for buying a flat, discovers that the price of the flat is $£ 10$ more than expected. Compare this with a case of a person who, before buying a coffee, is asked to pay $£ 10$ more than predicted. Apparently, an objectively equivalent extra-cost is experienced by both individuals. However, many would agree that the second person will be more upset. Examples like this describe how referent-dependency works. The CMPM extends this notion to the political domain. For this, the CMPM relies on an influential model of reference effects during decision-making (Rigoli, 2019) (note that different models are currently competing to explain reference effects (e.g., Louie et al., 2013; Louie \& Glimcher, 2017; Rigoli, 2019; Stewart et al., 2006); however, most accounts agree on the general principles, and hence the arguments proposed here would remain substantially equivalent if a different model was adopted). Following this framework, the CMPM defines the whole set of representations of society evoked in a given condition as the context; ultimately, this affects the subjective value associated with each representation (see below). Each representation of society $S_{k}$ is associated with a raw value $R\left(S_{k}\right)$ (mathematically described by a real number), which is attributed without considering the context. The model proposes that $R\left(S_{k}\right)$ is considered to calculate $V\left(S_{k}\right)$, corresponding to the subjective value associated with $S_{k}$ :

$$
V\left(S_{k}\right)=f_{\text {logistic }}\left(\frac{R\left(S_{k}\right)-\mu}{\sigma}\right)
$$

Where $\mu$ and $\sigma$ are the average and $S D$, respectively, across the raw values of all representations of society considered. Because $f_{\text {logistic }}$ corresponds to a logistic function, Equation 1 can also be formulated as: 


$$
V\left(S_{k}\right)=\frac{1}{1+e^{-\frac{R\left(S_{k}\right)-\mu}{\sigma}}}
$$

Note that Equation 1 and 2 imply $0 \leq V\left(S_{k}\right) \leq 1$. This formulation proposes that the subjective value associated with any representation of society is not absolute, but reference-dependent. To understand what this means, consider a set of representations of society described by different levels of GDP. The raw value $R\left(S_{k}\right)$ can be interpreted as the actual GDP of the society $S_{k}$, while the subjective value $V\left(S_{k}\right)$ can be understood as its value relative to the other societies considered. It is such subjective value which, according to the CMPM, is ultimately at the root of political motivation (see below). Two forms of reference effects ensue from Equation 1 and 2 (Figure 1). First, an effect exerted by the contextual average $\mu$ is implemented (Figure 1a), because the average is subtracted from $R\left(S_{k}\right)$. This implies that, when the contextual average is higher, $V\left(S_{k}\right)$ will be smaller. Specifically, $V\left(S_{k}\right)>0.5$ occurs when $R\left(S_{k}\right)>\mu$, while $V\left(S_{k}\right)<0.5$ occurs when $R\left(S_{k}\right)<\mu$. Second, the $S D$ of the contextual distribution $\sigma$ is also influential (Figure $1 \mathrm{~b}$ ). When the $S D$ is smaller, the distance in subjective value between two different representations will be magnified, so that the subjective value of one representation will be more far apart from the subjective value of another representation.

\section{Figure 1}

Relationship Between Raw and Subjective Value According to the CMPM for Different Parameters of the Model

(a) Effect of the contextual average

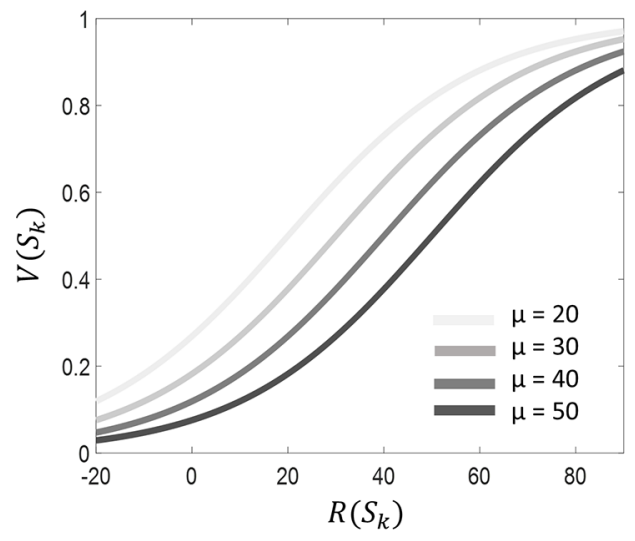

(b) Effect of the contextual SD

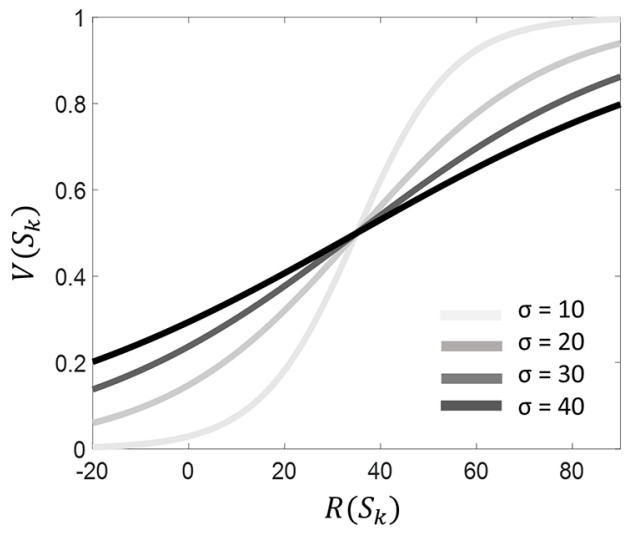

Note. (a) Predicted effect of average $\mu(\sigma=20)$. (b) Predicted effect of $S D \sigma(\mu=35)$.

The third CMPM assumption concerns how the motivation for performing a political action is eventually calculated. Influential mathematical models in cognitive psychology propose that the motivation for performing any action depends on the expected consequence of that action in comparison with the outcome expected without performing that action (Dayan, 2012; Maier \& Seligman, 1976; Rigoli et al., 2016a; Seligman, 1974). Again, this idea emphasises the comparative nature of cognition. As an illustrative example, consider a kid's motivation for going to buy a chocolate bar. This motivation is proposed to depend not only on the expected consequence of the action, but also on the expected consequence of not performing the action. For example, if the kid expects her grandparents to go to buy a chocolate bar anyway, performing versus not performing the action does not make much difference, and the motivation for action performance will be low. The CMPM captures this intuition by proposing that, although the set of representations of society (the context) might vary considerably, in all cases three fundamental representations of society are always considered. First, society is described as it is believed to be at the present time $\left(S_{\text {pres }}\right)$. Second, a possible society of the future is represented as emerging if people (or a certain group of people) performed an appropriate political action which is thought to create positive consequences $\left(S_{a c t}\right)$. For instance, society is represented as emerging after people supported a certain good party, or activated to prevent global warming, or joined a certain good protest movement, or after people expelled immigrants etc. Note this is a subjective representation of a future society which is evaluated as being positive, and which is thought to be conditional on performing an appropriate political action. Third, a possible 
society of the future is represented as emerging if people (or a certain group of people) did not perform an appropriate political action $\left(S_{\text {Noact }}\right)$. For instance, society is represented as emerging after people have not supported a certain good party, or have not activated to prevent global warming, or have not joined a certain good protest movement, or after people have not expelled immigrants etc. Like any other representation of society conceived, $S_{\text {pres }}$, $S_{\text {act }}$ and $S_{\text {Noact }}$ are associated with raw values $R\left(S_{\text {pres }}\right), R\left(S_{\text {act }}\right)$ and $R\left(S_{\text {Noact }}\right)$, respectively (note that by definition $R\left(S_{\text {Noact }}\right)<R\left(S_{\text {act }}\right)$ ). These can be considered together with Equation 1 to compute the subjective values, namely $V\left(S_{\text {pres }}\right), V\left(S_{\text {act }}\right)$ and $V\left(S_{\text {Noact }}\right)$, respectively (Figure 2) (note that $V\left(S_{\text {Noact }}\right)<V\left(S_{\text {act }}\right)$ ). Following influential mathematical theories of motivation (Dayan, 2012; Maier \& Seligman, 1976; Rigoli et al., 2016a; Seligman, 1974), our model proposes that, based on $V\left(S_{\text {Noact }}\right)$ and $V\left(S_{a c t}\right)$, a Motivation for Political Action (MPA) is derived (Figure 2):

$$
M P A=V\left(S_{\text {act }}\right)-V\left(S_{\text {Noact }}\right)
$$

The CMPM proposes that such MPA corresponds to the actual drive to perform the political action viewed as appropriate. Mathematically, this formulation requires that $0 \leq \mathrm{MPA} \leq 1$. Note that, because both $V\left(S_{\text {act }}\right)$ and $V\left(S_{\text {Noact }}\right)$ are estimated based on Equation 1 where reference effects are implemented, MPA is also the product of such effects. Hence the CMPM proposes a reference-dependent nature for political motivation, because MPA does not capture how much performing an appropriate political action is valuable in absolute terms, but in the context of other representations of society. Below, we will see when reference effects have important implications for MPA.

\section{Figure 2}

Graph Describing the Subjective Value Associated With the Fundamental Representations of Society Within a Context $\left(V\left(S_{\text {pres }}\right), V\left(S_{\text {act }}\right)\right.$ and V( $\left.\left(S_{\text {Noact }}\right)\right)$, as Estimated by the CMPM

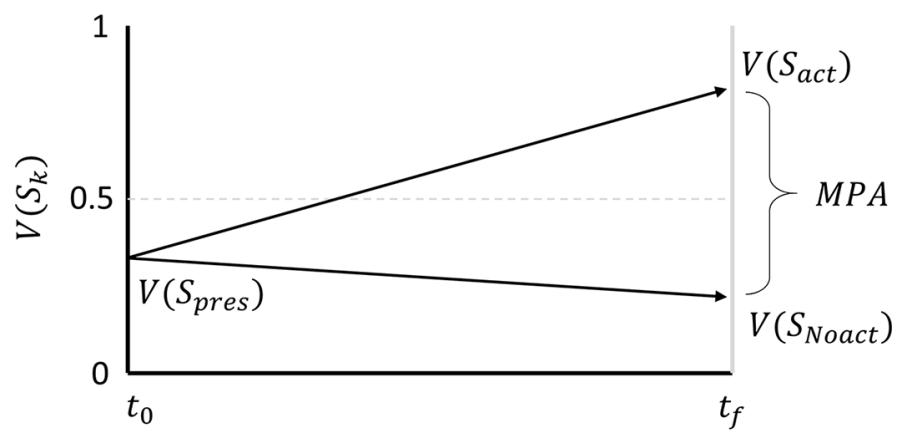

Note. The ensuing motivation for political action (MPA) is also reported. $t_{0}$ corresponds to the present time, while $t_{f}$ corresponds to the future.

In addition to determining MPA, the CMPM postulates that $V\left(S_{\text {act }}\right)$ and $V\left(S_{\text {Noact }}\right)$ are also central in determining the ensuing political mood (Figure 3). For this aspect, $V\left(S_{\text {pres }}\right)$ is also relevant. The political mood can be conceived as the affective state associated with specific values of $V\left(S_{\text {act }}\right), V\left(S_{\text {Noact }}\right)$, and $V\left(S_{\text {pres }}\right)$. The idea that mood derives from beliefs about important states of affairs is classical in cognitive psychology (Lazarus, 1982; Lazarus \& Smith, 1988). Here we formalise this notion in mathematical terms and apply this to the political domain, suggesting that political mood is the consequence of entertaining certain beliefs about society. Based on the different combinations of values for $V\left(S_{\text {act }}\right)$, $V\left(S_{\text {Noact }}\right)$, and $V\left(S_{\text {pres }}\right)$ (with high and low values corresponding to $>.5$ and $<.5$, respectively; namely corresponding to raw values higher and lower than the contextual average $\mu$, respectively), the CMPM identifies six main categories of political mood (note that cases where $V\left(S_{\text {act }}\right)<V\left(S_{\text {Noact }}\right)$ are not considered because $V\left(S_{\text {act }}\right)>V\left(S_{\text {Noact }}\right)$ by definition). When $V\left(S_{\text {pres }}\right)$ and $V\left(S_{\text {act }}\right)$ are both high and $V\left(S_{\text {Noact }}\right)$ is low, political anxiety would emerge (Figure 3a). In other words, political anxiety would arise when someone believes that the current society is good, but that a substantial threat is looming which can be avoided through political action. For example, this mood characterises ideologies which praise the existent society, view it as threatened by immigration, and believe that with an appropriate response (such as expelling immigrants) such threat can be avoided. When $V\left(S_{\text {act }}\right)$ is high and both $V\left(S_{\text {Noact }}\right)$ and $V\left(S_{\text {pres }}\right)$ are low, the 
CMPM proposes that political anger arises (Figure 3b). In other words, this mood would emerge when someone believes that the current society is bad but can largely improve with political action, though society is expected to remain bad without that action. For example, this mood would be expressed by movements who believe the current system is unjust but can be changed by their activism (though the system is expected to remain bad if they do not act). Note that the CMPM assumes that the difference between political anxiety and anger is that the former emerges when one believes that the current society is good, while the latter emerges when the current society is appraised as bad. Note also that both these political moods imply large MPA, because they are associated with $V\left(S_{\text {act }}\right)$ and $V\left(S_{\text {Noact }}\right)$ which are far apart. In other words, individuals experiencing political anxiety or anger would believe that political action can really make a difference.

Figure 3

Description of the Different Political Moods as Proposed by the CMPM

(a) Political anxiety

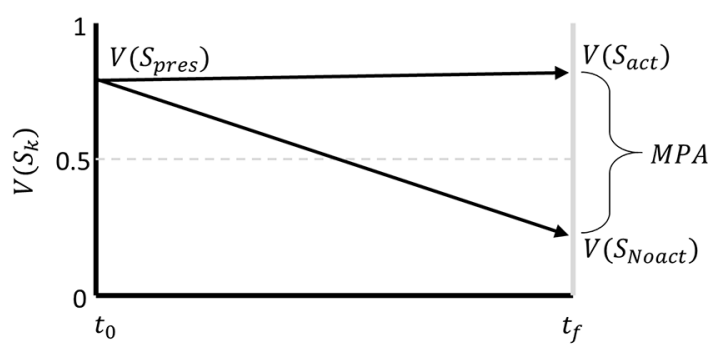

(c) Political depression

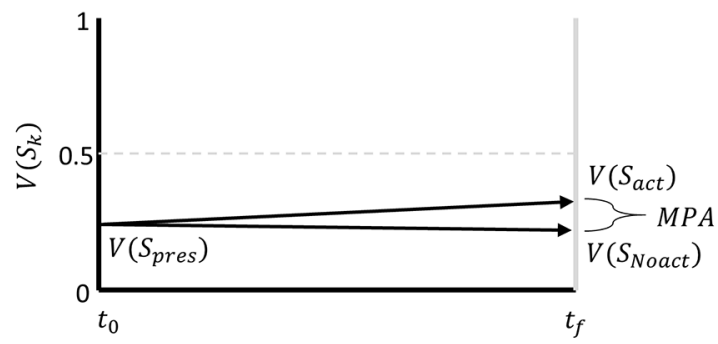

(e) Political hope

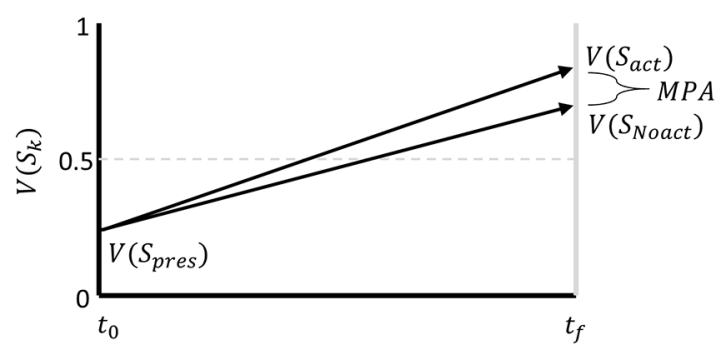

(b) Political anger

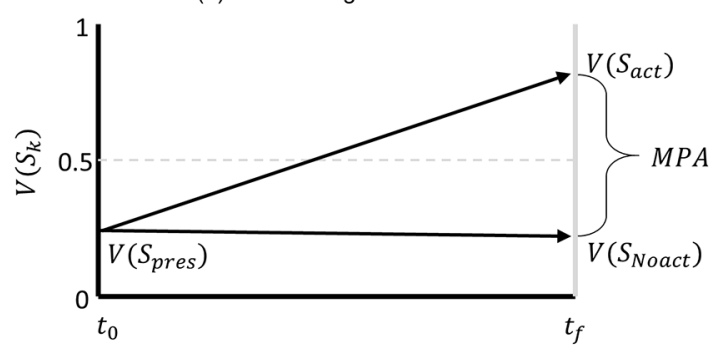

(d) Political desperation

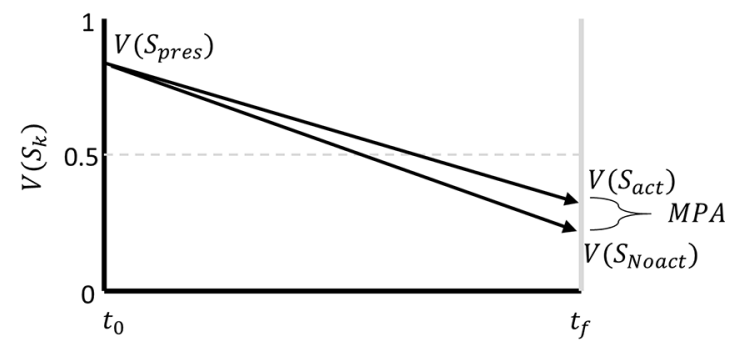

(f) Political serenity

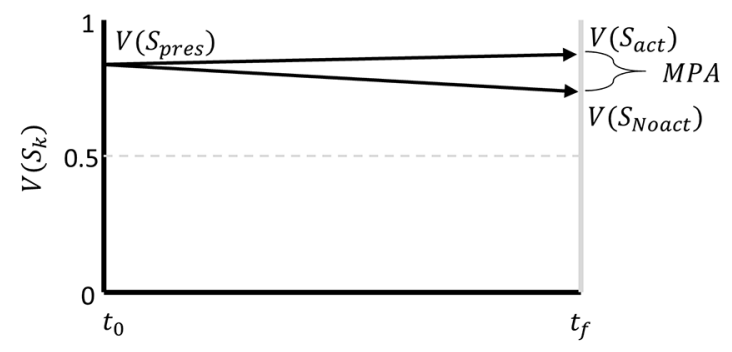

Note. Each graph describes the subjective value associated with the fundamental representations of society within an ideology $\left(V\left(S_{\text {pres }}\right), V\left(S_{\text {act }}\right)\right.$ and $\left.V\left(S_{\text {Noact }}\right)\right)$, as estimated by the CMPM. The ensuing motivation for political action (MPA) is also reported. $t_{0}$ corresponds to the present time, while $t_{f}$ corresponds to the future.

A third mood identified by the CMPM is political depression (Figure 3c). This occurs when $V\left(S_{\text {pres }}\right), V\left(S_{\text {act }}\right)$, and $V\left(S_{\text {Noact }}\right)$ are all low. In other words, an ideology inducing this mood would view not only the current society but also the future society as bad, and this independent of any political action. As a fourth mood, the CMPM proposes political desperation as arising when $V\left(S_{\text {pres }}\right)$ is high and both $V\left(S_{\text {act }}\right)$ and $V\left(S_{\text {Noact }}\right)$ are low (Figure 3d). In other words, this mood would 
arise when, though the present is viewed as positive, the future is predicted as being gloomy, and this independent of any political action. When $V\left(S_{\text {pres }}\right)$ is low and both $V\left(S_{\text {act }}\right)$ and $V\left(S_{\text {Noact }}\right)$ are high, the CMPM assumes that political hope emerges (Figure 3e). This would arise when, though the present is evaluated as negative, the future is predicted to improve substantially even if no political action is taken. Finally, political serenity is proposed as the mood emerging when $V\left(S_{\text {pres }}\right), V\left(S_{a c t}\right)$, and $V\left(S_{\text {Noact }}\right)$ are all high, in other words when the current society is believed to be good and to remain good in the future even if no political action is taken (Figure $3 \mathrm{f}$ ). Note that political depression, desperation, hope and serenity all arise when MPA is small (i.e., when $V\left(S_{\text {act }}\right)$, and $V\left(S_{\text {Noact }}\right)$ are close), in other words when political behaviour is thought to poorly affect society.

In short, we propose a model of political motivation which focuses on the role of different representations of society. The model proposes that the way these representations are evaluated is reference-dependent, in other words it is affected by the context (corresponding to all other representations of society evoked). Ultimately, these reference-dependent evaluations determine the motivation for performing a political action and the ensuing political mood. In the next section, we examine cases when reference-dependent processes proposed by the CMPM come into play.

\section{Reference Effects in Political Motivation}

In addition to the fundamental representations introduced above $\left(S_{\text {pres }}, S_{\text {act }}\right.$, and $\left.S_{\text {Noact }}\right)$, a variety of representations of society (each associated with a raw value) can be evoked in a given situation, including representations that are:

- historical, namely descriptions of society as it was in the past;

- fictive, namely descriptions thought to be impossible to apply to real life (such as utopias and dystopias);

- anthropological, namely descriptions of (past or present) society of another culture which are thought to be impossible to apply to the own society;

- counterfactual, namely representations of how society could be or could have been if different conditions applied, for instance if a different political action was taken.

The CMPM postulates that any representation of society will affect the subjective value attributed to all other representations according to Equation 1. The impact is twofold. First, a representation associated with high raw value will increase the contextual average $\mu$, hence (other things being equal) diminishing the subjective value of other representations. Second, a representation of society will also affect the contextual $S D \sigma$. When the $S D$ diminishes, the distance in subjective value of two representations will tend to increase. Below, we examine cases when, according to the CMPM, the context (namely the set of representations of society evoked) is predicted to elicit reference effects that impact on political motivation.

\section{Perfect Society}

First, consider contexts including a representation of a perfect society. The latter is often described as a state where all individuals occupy their right role, conflict is resolved, and happiness and satisfaction are ubiquitous. Sometimes, such perfect society corresponds to a golden age, namely to a past era which is now lost forever (as for instance in ancient Greek or Arcadian myths). Other times, such as in some religion traditions, a perfect society is projected to an eschatological future. Finally, a perfect society might be conceived as a possibility affordable through political action (as for instance in communist ideologies; see below). To examine the role of a perfect society within the CMPM, let us first examine a context where no perfect society is evoked (Figure 4a) and which is characterised by the following vector of raw values (each associated with one representation of society): $R\left(S_{x}\right)=60, R\left(S_{y}\right)=30, R\left(S_{z}\right)=40$, $R\left(S_{\text {act }}\right)=60, R\left(S_{\text {Noact }}\right)=30, R\left(S_{\text {pres }}\right)=40$. The numbers used in these examples are arbitrary: as long as certain constrains are respected, different numbers will produce results that are qualitatively similar. In this case, the important constrain is that all raw values are relatively close to one another; we will see that this does not apply when a perfect society is evoked (see below). Applying Equation 1, we obtain $V\left(S_{\text {act }}\right)=0.748, V\left(S_{\text {Noact }}\right)=0.252, V\left(S_{\text {pres }}\right)=0.590$, and $M P A=0.496$. This can be described as a condition of political anxiety, because both $V\left(S_{\text {act }}\right)$ and $V\left(S_{\text {pres }}\right)$ are high and $V\left(S_{\text {Noact }}\right)$ is low. 
Now let us focus on a context where a perfect society corresponds to a lost golden age, for example where $S_{x}$ describes a perfect society. How does the CMPM characterise this? The answer is that a perfect society will be associated with a raw value which is an outlier described by a high number (again, the specific number is not important here, as long as it is a positive outlier). For example, this can be modelled by assigning $R\left(S_{x}\right)=600$ rather than $R\left(S_{x}\right)=60$. Applying Equation 1 to the new vector, we now obtain $V\left(S_{\text {act }}\right)=0.419, V\left(S_{\text {Noact }}\right)=0.387, V\left(S_{\text {pres }}\right)=0.408$, and $M P A=0.032$ (Figure $4 \mathrm{~b})$. This describes a condition of political depression, because $V\left(S_{\text {act }}\right), V\left(S_{\text {pres }}\right)$ and $V\left(S_{\text {Noact }}\right)$ are all low. The reason why, after including a golden age, $V\left(S_{\text {act }}\right)$ and $V\left(S_{\text {pres }}\right)$ decrease is because the contextual average $\mu$ increases. However, inclusion of a perfect society also increases the $S D \sigma$. This leads $V\left(S_{\text {Noact }}\right)$ to approach 0.5 , hence increasing from 0.252 to 0.387 . Consequently, the MPA also decreases. In sum, according to the CMPM, contexts where a perfect society is conceived as a lost golden age will tend to elicit political depression. Importantly, this prediction is the consequence of the specific reference effects proposed by the CMPM. For example, these reference effects explain why the MPA is now small $(M P A=0.032)$, while in the previous scenario (equivalent except for the absence of a golden age - i.e., where $\left.R\left(S_{x}\right)=60\right)$ it was large $(M P A=0.496)$.

\section{Figure 4}

Examples of Application of the CMPM in the Case of Contexts Including a Perfect Society (Except for (a), Where no Perfect Society Is Represented)

(a)

$R\left(S_{x}\right)=60 ; R\left(S_{y}\right)=30 ; R\left(S_{z}\right)=40 ;$

$R\left(S_{\text {act }}\right)=60 ; R\left(S_{\text {Noact }}\right)=30 ; R\left(S_{\text {pres }}\right)=40$

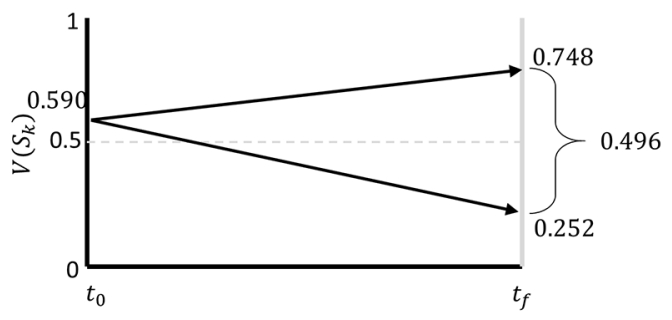

(c)

$R\left(S_{x}\right)=60 ; R\left(S_{y}\right)=30 ; R\left(S_{z}\right)=40 ;$

$R\left(S_{\text {act }}\right)=600 ; R\left(S_{\text {Noact }}\right)=580 ; R\left(S_{\text {pres }}\right)=40$

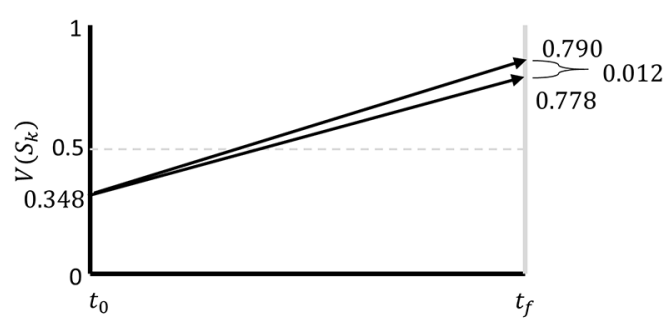

(b)

$R\left(S_{x}\right)=600 ; R\left(S_{y}\right)=30 ; R\left(S_{z}\right)=40 ;$

$R\left(S_{\text {act }}\right)=60 ; R\left(S_{\text {Noact }}\right)=30 ; R\left(S_{\text {pres }}\right)=40$

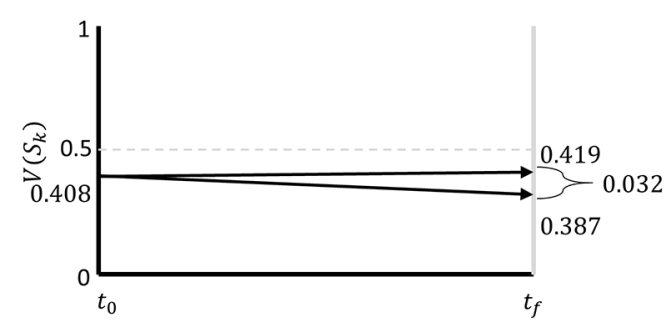

(d)

$$
\begin{gathered}
R\left(S_{x}\right)=60 ; R\left(S_{y}\right)=30 ; R\left(S_{z}\right)=40 \\
R\left(S_{\text {act }}\right)=600 ; R\left(S_{\text {Noact }}\right)=30 ; R\left(S_{\text {pres }}\right)=40
\end{gathered}
$$

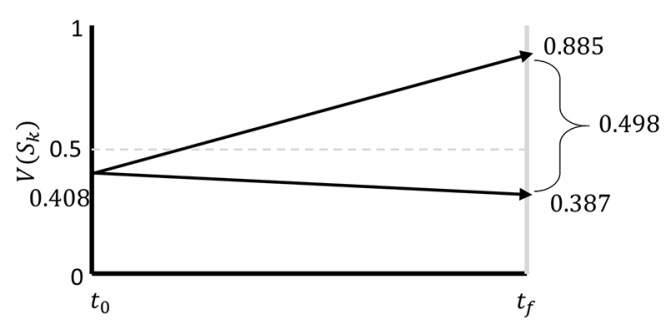

Note. For each example, the vector of raw values is reported above. Each graph describes the subjective value associated with the fundamental representations of society within a context $\left(V\left(S_{\text {pres }}\right), V\left(S_{\text {act }}\right)\right.$ and $\left.V\left(S_{\text {Noact }}\right)\right)$, as estimated by the CMPM. The ensuing motivation for political action (MPA) is also reported. $t_{0}$ corresponds to the present time, while $t_{f}$ corresponds to the future.

Let us now consider a context where a perfect society is framed in eschatological terms and is projected to the future. The CMPM captures this by treating both $R\left(S_{\text {act }}\right)$ and $R\left(S_{\text {Noact }}\right)$ as outliers. This is because, in an eschatological perspective, the perfect society will materialize independent of any political action. This is reflected in the vector $R\left(S_{x}\right)=60$, $R\left(S_{y}\right)=30, R\left(S_{z}\right)=40, R\left(S_{\text {act }}\right)=600, R\left(S_{\text {Noact }}\right)=580, R\left(S_{\text {pres }}\right)=40$. Applying Equation 1, one obtains $V\left(S_{\text {act }}\right)=0.790$, $V\left(S_{\text {Noact }}\right)=0.778, V\left(S_{\text {pres }}\right)=0.348$, and $M P A=0.012$ (Figure 4c). This reflects a condition of political hope, where both $V\left(S_{\text {act }}\right)$ and $V\left(S_{\text {Noact }}\right)$ are high, and both $V\left(S_{\text {pres }}\right)$ and MPA are low. As a third example, let us analyse a context where a perfect society is conceived as a future possibility affordable by politics. We can represent this adopting the vector $R\left(S_{x}\right)=60, R\left(S_{y}\right)=30, R\left(S_{z}\right)=40, R\left(S_{\text {act }}\right)=600, R\left(S_{\text {Noact }}\right)=30, R\left(S_{\text {pres }}\right)=40$. Note that now $R\left(S_{\text {act }}\right)=600$, but 
$R\left(S_{\text {Noact }}\right)=30$. In other words, a perfect society is expected to materialise only if an appropriate political action is taken. Applying Equation 1, we obtain $V\left(S_{\text {act }}\right)=0.885, V\left(S_{\text {Noact }}\right)=0.387, V\left(S_{\text {pres }}\right)=0.408$, and $M P A=0.498$ (Figure 4d). This can be described as a condition of political anger, because $V\left(S_{\text {pres }}\right)$ and $V\left(S_{\text {Noact }}\right)$ are low, but $V\left(S_{\text {act }}\right)$ and MPA are high. Finally, there are contexts where a perfect society might be located in the past as a golden age and believed to be reproducible in the future by performing an appropriate action. For instance, this context is associated to the fascist ideology, which viewed the Roman empire as a golden age which could be revived by Italian imperialism. This condition is modelled by the vector $R\left(S_{x}\right)=600, R\left(S_{y}\right)=30, R\left(S_{z}\right)=40, R\left(S_{\text {act }}\right)=600, R\left(S_{\text {Noact }}\right)=30, R\left(S_{\text {pres }}\right)=40$. Applying Equation 1, we obtain $V\left(S_{\text {act }}\right)=0.784, V\left(S_{\text {Noact }}\right)=0.338, V\left(S_{\text {pres }}\right)=0.354$, and $M P A=0.446$ (Figure 5a). This context elicits a state of political anger which is analogous to contexts where a golden age is absent and a future perfect society is conditional on political action.

Figure 5

Examples of Application of the CMPM in the Case of Contexts Including a Catastrophic Society (Except for (a), Where a Perfect Society Is Represented)

(a)

$$
\begin{gathered}
R\left(S_{x}\right)=600 ; R\left(S_{y}\right)=30 ; R\left(S_{z}\right)=40 ; \\
R\left(S_{\text {act }}\right)=600 ; R\left(S_{\text {Noact }}\right)=30 ; R\left(S_{\text {pres }}\right)=40
\end{gathered}
$$

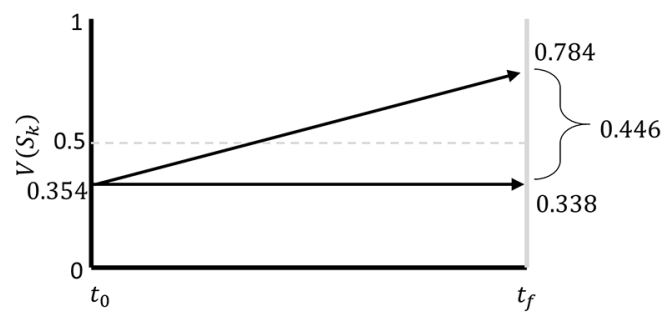

(c) $R\left(S_{x}\right)=60 ; R\left(S_{y}\right)=30 ; R\left(S_{z}\right)=40 ;$ $R\left(S_{\text {act }}\right)=-580 ; R\left(S_{\text {Noact }}\right)=-600 ; R\left(S_{\text {pres }}\right)=40$

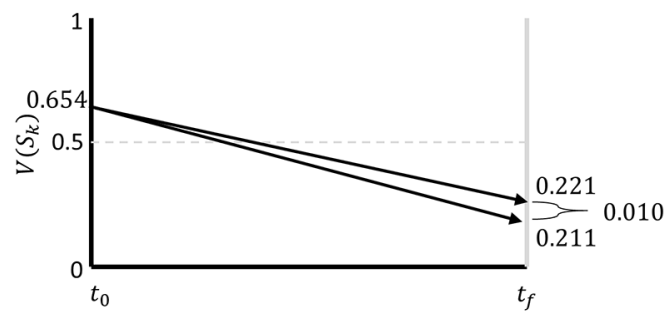

(b) $R\left(S_{x}\right)=-600 ; R\left(S_{y}\right)=30 ; R\left(S_{z}\right)=40$ $R\left(S_{\text {act }}\right)=60 ; R\left(S_{\text {Noact }}\right)=30 ; R\left(S_{\text {pres }}\right)=40$

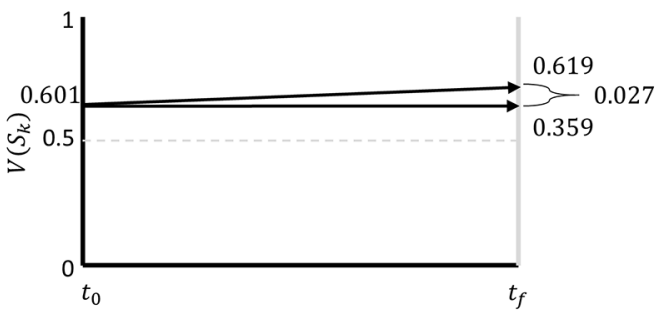

(d)

$$
\begin{gathered}
R\left(S_{x}\right)=60 ; R\left(S_{y}\right)=30 ; R\left(S_{z}\right)=40 ; \\
R\left(S_{\text {act }}\right)=600 ; R\left(S_{\text {Noact }}\right)=-600 ; R\left(S_{\text {pres }}\right)=40
\end{gathered}
$$

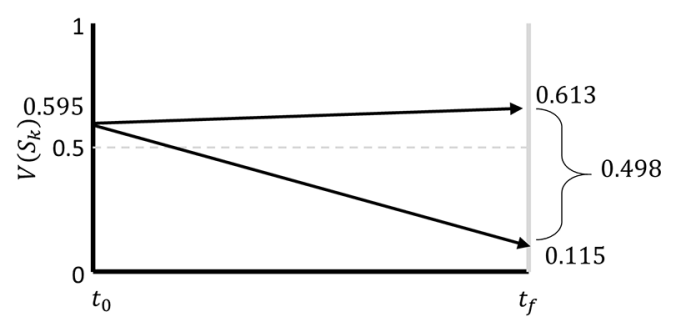

Note. For each example, the vector of raw values is reported above. Each graph describes the subjective value associated with the fundamental representations of society within a context $\left(V\left(S_{\text {pres }}\right), V\left(S_{\text {act }}\right)\right.$ and $V\left(S_{\text {Noact }}\right)$ ), as estimated by the CMPM. The ensuing motivation for political action (MPA) is also reported. $t_{0}$ corresponds to the present time, while $t_{f}$ corresponds to the future.

\section{Catastrophic Society}

Another case where reference effects are critical is when a catastrophic society is evoked, often depicted as a state of pervasive injustice, disorder and suffering. Let us first consider cases where a catastrophic society is located in the past. For example, some early modern philosophers (e.g., Hobbes, 1642/1998) thought that humanity had moved from a natural condition of abuse and injustice (a form of catastrophic society) to a civilized condition where substantial improvement was ensured by law and social institutions. The way CMPM treats a catastrophic society is similar to the treatment of a perfect society, but with opposite sign. In other words, within CMPM, the raw value assigned to a catastrophic society corresponds to an outlier associated with a low number (again, the specific number is not important here, as long as it is a negative outlier). An example of a context locating a catastrophic society $S_{x}$ in the past can be described by the vector $R\left(S_{x}\right)=-600, R\left(S_{y}\right)=30, R\left(S_{z}\right)=40, R\left(S_{\text {act }}\right)=60, R\left(S_{\text {Noact }}\right)=30, R\left(S_{\text {pres }}\right)=40$. Applying Equation 1, we obtain $V\left(S_{\text {act }}\right)=0.619, V\left(S_{\text {Noact }}\right)=0.591, V\left(S_{\text {pres }}\right)=0.601$, and $M P A=0.027$ (Figure $5 \mathrm{~b}$ ). This corresponds 
to a mood of political serenity, because $V\left(S_{\text {pres }}\right), V\left(S_{\text {Noact }}\right)$ and $V\left(S_{\text {act }}\right)$ are all high, and MPA is low. Consider now a context where a catastrophic society is expected in the future independent of any political action, as for instance in some apocalyptic religions. The CMPM describes this assigning $R\left(S_{\text {act }}\right)=-580$ and $R\left(S_{\text {Noact }}\right)=-600$, hence resulting in the vector $R\left(S_{x}\right)=60, R\left(S_{y}\right)=30, R\left(S_{z}\right)=40, R\left(S_{\text {act }}\right)=-580, R\left(S_{\text {Noact }}\right)=-600, R\left(S_{\text {pres }}\right)=40$. Applying Equation 1 , we obtain $V\left(S_{\text {act }}\right)=0.221, V\left(S_{\text {Noact }}\right)=0.211, V\left(S_{\text {pres }}\right)=0.654$, and $M P A=0.010$ (Figure 5c). This describes a condition of political desperation, because $V\left(S_{\text {act }}\right)$ and $V\left(S_{\text {Noact }}\right)$ are both low, $V\left(S_{\text {pres }}\right)$ is high, and MPA is low. As a third case, consider contexts where a catastrophic society represents a threat which can be avoided through political action. For example, some parties view immigration as a potential disaster which can be avoided by expelling all irregular immigrants. The CMPM describes this assigning a very low raw value to $S_{\text {Noact }}$ only, for example setting $R\left(S_{\text {Noact }}\right)=-600$. This results in the vector $R\left(S_{x}\right)=60, R\left(S_{y}\right)=30, R\left(S_{z}\right)=40, R\left(S_{\text {act }}\right)=60, R\left(S_{\text {Noact }}\right)=-600, R\left(S_{\text {pres }}\right)=40$. Applying Equation 1, we obtain $V\left(S_{\text {act }}\right)=0.613, V\left(S_{\text {Noact }}\right)=0.115, V\left(S_{\text {pres }}\right)=0.595$, and $M P A=0.498$ (Figure 5d), which corresponds to a mood of political anxiety.

\section{Beliefs About Historic Change}

The CMPM is also relevant when examining beliefs about historic change. With this regard, some political views conceive historic change as progress (i.e., as a steady movement towards better societies) and other views conceive historic change as decadence (i.e., as a steady movement towards worse societies). To examine how the CMPM distinguishes these two conditions, consider two contexts both associated with $R\left(S_{\text {act }}\right)=65, R\left(S_{\text {Noact }}\right)=35, R\left(S_{\text {pres }}\right)=50$. However, the first context is characterised by $R\left(S_{x, 1}\right)=10, R\left(S_{y, 1}\right)=20, R\left(S_{z, 1}\right)=30$, in other words it conceives historic change as progress, while the second context is characterised by $R\left(S_{x, 2}\right)=90, R\left(S_{y, 2}\right)=80, R\left(S_{z, 2}\right)=70$, in other words it conceives historic change as decadence. Note that, comparing the two contexts, the contextual average $\mu$ changes, while the contextual $S D \sigma$ remains equal. Applying Equation 1 to the first context, we obtain $V\left(S_{\text {act }}\right)=0.792, V\left(S_{\text {Noact }}\right)=0.566$, $V\left(S_{\text {pres }}\right)=0.690, M P A=0.226$ (Figure 6a). Applying Equation 1 to the second context, we obtain $V\left(S_{\text {act }}\right)=0.434$, $V\left(S_{\text {Noact }}\right)=0.208, V\left(S_{\text {pres }}\right)=0.310, M P A=0.226$ (Figure 6a). The difference is that all subjective values will be higher for the context associated with progress compared to the context associated with decadence. This reflects the effect of contextual average $\mu$, which varies across the two different contexts. Note that the distance between subjective values does not vary (and in fact MPA does not very either), because the contextual $S D \sigma$ remains unchanged across contexts. In summary, reference effects postulated by CMPM predict that, when compared to views believing in decadence, views believing in progress will perceive the present and future society as better in subjective terms.

Figure 6

(a) Examples of Application of the CMPM in the Case of Contexts Where History Is Viewed as Progress or Where History Is Viewed as Decadence (See Main Text for the Vectors of Raw Values). (b) Application of the CMPM to the Communist Manifesto
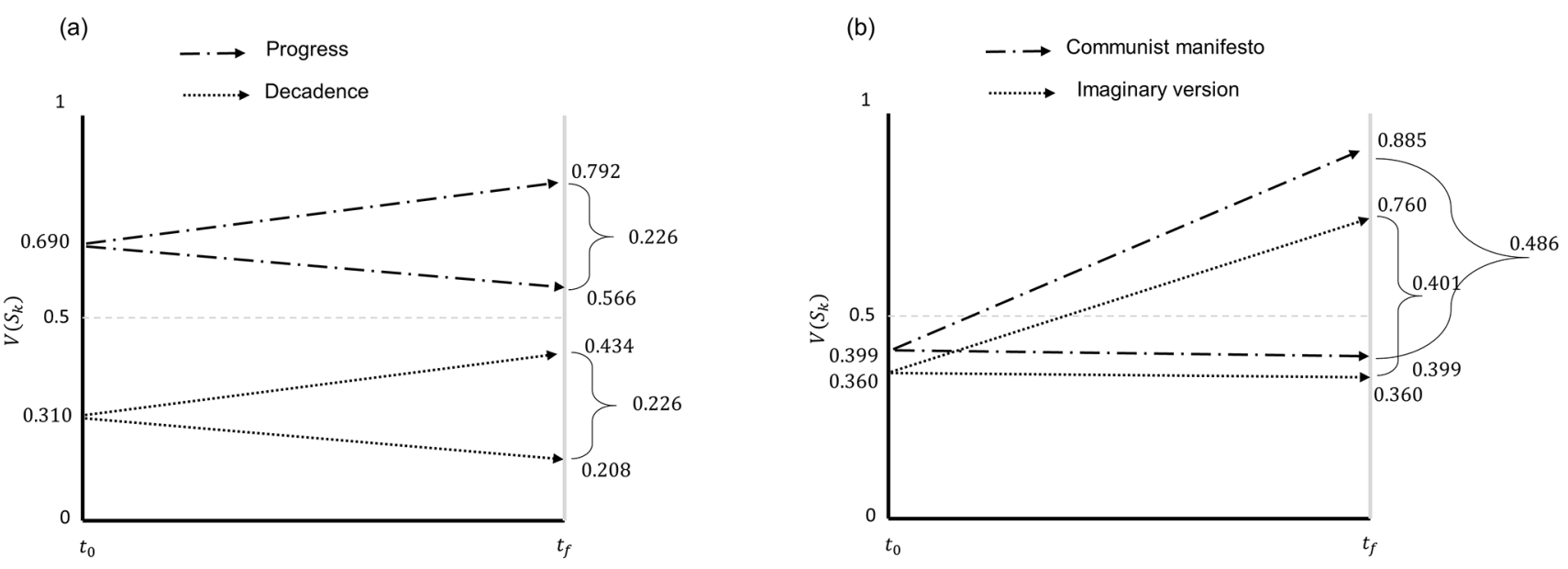
Note. The actual manifesto is compared with an imaginary version where only $V\left(S_{\text {pres }}\right), V\left(S_{\text {act }}\right)$ and $V\left(S_{\text {Noact }}\right)$ are included as representations (see main text for vectors of raw values). For both (a) and (b), the graph describes the subjective value associated with the fundamental representations of society within a context $\left(V\left(S_{\text {pres }}\right), V\left(S_{\text {act }}\right)\right.$ and $\left.V\left(S_{\text {Noact }}\right)\right)$, as estimated by the CMPM. The ensuing motivation for political action (MPA) is also reported. $t_{0}$ corresponds to the present time, while $t_{f}$ corresponds to the future.

In short, the CMPM implicates that the motivational and affective aspects of political beliefs are influenced by reference effects which depend on the whole set of representations of society evoked. Here we have examined how reference effects unfold depending on how historical change is appraised, and on whether a perfect or catastrophic society is conceived. Our analysis has focused on historical representations of society, although often other types of representations (fictive, anthropological, counterfactual) are also evoked. The CMPM proposes that similar processes will be at play also in these cases. The next section will examine how the model can be connected to previous theoretical research with an interest in political motivation.

\section{Implications for Theoretical Research}

The CMPM is relevant for a variety of research lines with an interest in political motivation, including social identity theory (Hogg, 2018; Mackie et al., 2000; Mackie \& Smith, 2002; Tajfel, 1981; Tajfel \& Turner, 1979; Turner et al., 1987), relative deprivation theory (Crosby, 1976; Davies, 1962; Folger, 1986; Gurr, 1970; Runciman, 1966; Smith \& Pettigrew, 2015; Stouffer et al., 1949), research on collective action (Davies, 1962; Gurr, 1970; Klandermans \& van Stekelenburg, 2013; Olson, 1965; Van Zomeren et al., 2008), and research on the psychology of morality and justice (Deutsch, 1975; Doris, 2010; Haidt, 2007; Tyler, 2003). The CMPM offers a novel mathematical perspective that can potentially help in re-casting aspects of these theories in a formal fashion. Here we will discuss the CMPM in the context of this research. Because this literature is vast, the focus will be only on some of the most relevant contributions for the CMPM.

Social identity theory analyses the processes whereby individuals identify with groups and develop in-group and out-group attitudes (Hogg, 2018; Tajfel, 1981; Tajfel \& Turner, 1979; Turner et al., 1987). Within this research tradition, Intergroup emotions theory (Mackie et al., 2000; Mackie \& Smith, 2002) integrates social identity theory and models of emotion. According to this, when group identity is salient, a social event generates a cognitive appraisal which in turn elicits an appropriate emotional response and motivational tendency. The notion that a cognitive appraisal is at the root of emotion and motivation is shared by the CMPM; in the latter, the cognitive appraisal is casted as a set of evaluations attributed to different representations of society, from which mood and motivation arise. The CMPM can be conceived as an extension of Intergroup emotions theory (Mackie et al., 2000; Mackie \& Smith, 2002) in as much as (i) it extends the focus from intergroup dynamics to the political domain (by proposing that representations of society and their associated values are key players in this domain), (ii) it emphasises reference effects which are not considered by Intergroup emotions theory, and (iii) it offers a formal mathematical treatment of key concepts (absent in Intergroup emotions theory) such as political motivation.

The CMPM embraces the notion of referent cognition, which guides theories in a variety of psychological domains (e.g., Helson, 1948; Parducci, 1965; Kahneman \& Tversky, 1979). Hence, the CMPM has analogies with theories in political and social psychology which rely on referent cognition. These theories include the relative deprivation model, which considers subjective evaluations as comparative in nature (Crosby, 1976; Davies, 1962; Folger, 1986; Runciman, 1966; Smith \& Pettigrew, 2015; Stouffer et al., 1949). In this perspective, an important distinction is between self-related deprivation (Crosby, 1976; Runciman, 1966), which compares the self against other individuals (or against the self in the past), and group-related deprivation, which compares in-group versus out-group conditions (Pettigrew et al., 2008; Runciman, 1966). The latter type of relative deprivation is closer to ideas proposed by the CMPM, where the focus is on the political domain and hence more on groups rather than single individuals. Inspired by relative deprivation, another proposal (Folger, 1986) has emphasised that comparisons do not always involve objective references (such as other people or past conditions), but they can be based on fictive references (such as counterfactual scenarios). This idea is shared by the CMPM, where representations of imaginary societies can be at play. The CMPM can be conceived as an extension of relative deprivation theory and similar accounts in as much as (i) it extends the analysis beyond 
intergroup comparison (which is the focus of relative deprivation theory and similar accounts), encompassing political scenarios where intergroup comparison is not involved (by focusing on representations of society rather than on group comparisons), (ii) it proposes a sophisticated taxonomy of political mood (relative deprivation theory has rarely explored this besides frustration and anger; Crosby, 1976), (iii) it explores further the role of reference effects (by following recent literature on this subject; Louie et al., 2013; Louie \& Glimcher, 2017; Rigoli, 2019; Stewart et al., 2006), and (iii) it offers a revised view of motivation which takes into account not only the level of deprivation but also how effective a political action is expected to be. The latter point is particularly important: according to most relative deprivation accounts, motivation depends only on how relatively deprived individuals feel (the higher the deprivation, the higher the motivation). However, empirical evidence has shown that this is insufficient for explaining motivation, and that aspects such as perception of action efficacy are also critical (Corcoran et al., 2011; Dalton et al., 2010; Oberschall, 1973; Van Zomeren et al., 2004). The CMPM formalizes the concept of perception of action efficacy as corresponding to the MPA (namely, the difference in value between performing and not performing the action).

The CMPM is also relevant for research on collective action, especially regarding the question of why people participate in social movements. Early accounts (some based on relative deprivation) proposed grievances as the key factor underlying the motivation to support social movements (Davies, 1962; Gurr, 1970; Klandermans \& van Stekelenburg, 2013). Based on evidence showing that aggrieved people often do not participate in social movements, mobilization theories (Klandermans \& van Stekelenburg, 2013; Oberschall, 1973; Olson, 1965; Van Zomeren et al., 2008) argue that perception of political efficacy (e.g., about political skills and resources) is also critical (an arguments supported empirically; Corcoran et al., 2011; Dalton et al., 2010; Oberschall, 1973; Van Zomeren et al., 2004). Furthermore, recent scholars emphasise that beliefs about grievances and efficacy are not objective but subjective in nature (Klandermans \& van Stekelenburg, 2013; Van Zomeren et al., 2008). The CMPM fits with theories that, for explaining the motivation to participate in social movements, rely on the notion of grievances and efficacy, and conceive these as subjective constructs. Within the CMPM grievances can be described by the subjective values attributed to the different representations of society, while efficacy is formalized as the very concept of political motivation. By implementing referent evaluation, the CMPM proposes that both grievances and efficacy are subjective, namely they ultimately depend on the context (which is defined by the representations evoked in each situation). The CMPM can be conceived as an extension of theories of collective action in as much as (i) it offers a formal mathematical treatment of key concepts and their relation (absent in previous models of collective action), for example offering a formal description of action efficacy (interpreted as MPA), (ii) it proposes a link between beliefs and mood, and (iii) it explores the role of reference effects further (by following recent literature on this subject; Louie et al., 2013; Louie \& Glimcher, 2017; Rigoli, 2019; Stewart et al., 2006).

Finally, the CMPM is relevant for research in the psychology of morality and justice (Deutsch, 1975; Doris, 2010; Haidt, 2007; Tyler, 2003). In this area, an important question is how judgements about morality and justice motivate behaviour. The CMPM addresses this question in the political domain. According to the CMPM, the incentive value attached to each representation of society integrates two aspects. First, it depends on self-interest considerations. Second, it also considers judgements about what is morally right or just. For example, the personal GDP might influence the self-interest component, while the Gini index (reflecting wealth inequalities among people) might affect the ethical component; the resulting value attached to a representation of society integrates both (with some people weighting more the self-interest versus the ethical component, and vice versa for other people). The CMPM offers a mathematical description of the processes through which self-interest and ethical evaluations ultimately motivate political action (note that the model does not focus on why certain societies are judged as morally right or just, but on the effects of these judgements upon political motivation).

In short, the CMPM can contribute to theoretical research in several areas within political psychology. In general, the model helps re-casting aspects of previous theories in mathematical terms. This approach is useful for at least two reasons. First, it allows to express the concepts in a more formal and clear way. Second, this approach helps integrating different research areas because it shows that apparently different ideas can often be reduced to the same formal concept. Below, we will now turn to assessing the CMPM in the context of empirical research. 


\section{Potential Empirical Research}

One central aim of the CMPM is to inspire empirical research. To this aim, we propose two broad lines of investigation. First, some fundamental assumptions of the theory need to be validated empirically. For example, it remains to be established to what extent representations of future societies (i.e, $S_{\text {act }}$ and $S_{\text {Noact }}$ ) impact on political motivation and (together with $S_{\text {pres }}$ ) mood (at least for people who care about politics). Also, it remains to be assessed empirically whether reference effects implicated by the CMPM are at play in political thinking. With this regard, models similar to the CMPM have been investigated in the context of value-based decision making and have received substantial empirical support (Louie et al., 2013; Louie \& Glimcher, 2017; Rigoli, 2019; Rigoli et al., 2016b; Stewart, Reimers, \& Harris, 2015). In particular, evidence highlights both an effect exerted by the contextual mean and $S D$ during decision-making (Rigoli et al., 2016a). However, whether similar reference effects can be identified also when investigating the political domain remains an open question. For addressing this, experimental research could examine whether participants' evaluation of society and political motivation (e.g., manifested as willingness to engage in political actions) change after manipulating descriptions of society.

A second line of research consists in applying the CMPM to predict individuals' political motivation. The CMPM assumes that representations of society, their raw and subjective value, motivation for political action and political mood are psychological constructs (i.e., they are at play in the "mind" of an individual) that can be measured indirectly, for example with questionnaires. To measure these variables, participants could be asked to evaluate society at different moments in history and to predict future society. Data could then be interpreted to infer the psychological constructs postulated by the CMPM and henceforth to predict participants' will to engage in political behaviour in the future (e.g., voting or protesting). In addition to such observational studies, we suggest that the CMPM can also be applied to interpret political speeches or political writings such as political manifestos. Although this approach allows only a qualitative description, an important advantage is that it permits applying the CMPM also to past political thinking.

To illustrate how the CMPM can be applied to political writings, here we propose an interpretation of the Communist manifesto (one of the most influential political writings in history; Marx \& Engels, 1848/2002) based on the CMPM. The first step is to identify the different representations of society depicted in the writing. Western capitalistic society of the mid- $19^{\text {th }}$ century, the time when the manifesto was published, is analysed in detail. The key aspect of that society is the conflict between the bourgeoisie, a class viewed as dominant, and the proletariat, a class viewed as exploited. According to the communist manifesto, class conflict is not only the key process driving contemporary society, but also human history in general. This concept is adopted also to describe the Middle Ages, where the conflict is identified among feudal lords, town-people, and serfs. While mid-19 ${ }^{\text {th }}$ century capitalistic and Middle Ages societies are discussed in depth, ancient Roman society is only mentioned briefly (for example in the first page), yet it is still interpreted with the lenses of class conflict (in this case, among patricians, plebeians, and slaves). Noteworthy, the first page of a later edition of the manifesto reports a note which focuses on pre-historic society. This is described as a primitive communist organization where individuals are not divided in classes (and hence class conflict is absent) and ownership is shared. In addition to focusing on the present and past, the manifesto offers a detailed description of the future society predicted to emerge as consequence of proletarian straggle. The manifesto predicts first a dictatorship of the proletariat, in which this social class takes control over the state and the economy, followed by a communist society where state and social class vanish and "the free development of each is the condition for the free development of all" (Marx \& Engels, 1848/2002). In summary, the manifesto offers a description of society during pre-history, ancient Rome, Middle Ages, mid- $19^{\text {th }}$ century capitalism, and during the future communist era.

Adopting the perspective offered by the CMPM, we can interpret the representation of the mid- $19^{\text {th }}$ century capitalism society as $S_{\text {pres}}$, and we can label representation of past societies in the pre-history, ancient Rome, and Middle Ages as $S_{\text {pre hist }}, S_{\text {Rome }}, S_{\text {mid age }}$, respectively. Regarding the future communist era, this can be interpreted as the society expected to occur if an appropriate political action is taken $\left(S_{\text {act }}\right)$. This captures the notion that a communist society can be realised, but only if the proletariat keeps fighting the bourgeoisie. Note that the manifesto never describes a political scenario which would occur if the proletariat did not engage in class struggle. This might be because the manifesto appears to assume that proletarians have the power and the interest to defeat the bourgeoisie, and hence that they will surely engage in appropriate class straggle. In a CMPM perspective, because $S_{\text {Noact }}$ is never described 
explicitly, it needs to be inferred indirectly. Here, we assume that the manifesto implicitly assumes that society would remain like mid-1 $9^{\text {th }}$ century capitalism if proletarians did not engage in class straggle, hence we set $S_{\text {Noact }}=S_{\text {pres }}$. Once different representations of society are identified, the CMPM requires us to infer the raw value associated with each. We acknowledge that an inference based on political writings such as the Communist manifesto risks to be highly subjective. However, we argue that a qualitative picture can often be identified. From reading the manifesto, it is evident that the raw value attributed to $S_{\text {pre hist }}, S_{\text {Rome }}, S_{\text {mid age }}$, and $S_{\text {pres }}, S_{\text {Noact }}$ is similar (remember that $S_{\text {Noact }}=S_{\text {pres }}$ ). For example, comparing $S_{\text {mid age }}$ and $S_{\text {pres }}$, sometimes the manifesto seems to implicate that the former is morally better. We can read that "In one word, for exploitation, vailed by religion and political illusions, it [the bourgeoisie] has substituted naked, shameless, direct, brutal exploitation" (Marx \& Engels, 1848/2002). Other times, the manifesto seems to suggest the opposite, when it writes that "[the bourgeoisie] has been the first to show what man's activity can bring about. It has accomplished wonders far surpassing Egyptian pyramids, Roman aqueducts, and Gothic cathedrals" (Marx \& Engels, 1848/2002). Moreover, the appraisal of $S_{\text {pre hist }}$ is unclear, because this representation is never evaluated explicitly. On the one hand, $S_{\text {pre hist }}$ is associated with lack of civilization (which is usually considered as negative in the manifesto). On the other, it is characterised by primitive communism and lack of class exploitation. Overall, these considerations suggest that the manifesto evaluates roughly equally all representations except $S_{a c t}$. Hence, we can assign the same raw value to all representations except $S_{\text {act }}$, and set $R\left(S_{\text {pre hist }}\right)=R\left(S_{\text {Rome }}\right)=R\left(S_{\text {mid age }}\right)=R\left(S_{\text {pres }}\right)=$ $R\left(S_{\text {Noact }}\right)=40$ (again, the specific number is not important here, as long as these representations have equal raw value). Conversely, the manifesto emphasises the uniqueness of future communist society. This is viewed as economic and technological development combined with lack of class exploitation, a condition predicted to allow true individual and social fulfilment. In the perspective of the CMPM, this fits with a description of a perfect society which can be described by setting $R\left(S_{a c t}\right)=600$ (again, the specific number is not important here, as long as it is a positive outlier).

Once the raw values are inferred, we can apply Equation 1 to estimate subjective values, obtaining $V\left(S_{\text {act }}\right)=0.885$, $V\left(S_{\text {Noact }}\right)=0.399, V\left(S_{\text {pres }}\right)=0.399$, and $M P A=0.486$ (Figure 6b). This captures a mood of political anger, because $V\left(S_{\text {Noact }}\right)$ and $V\left(S_{\text {pres }}\right)$ are both low, while $V\left(S_{\text {act }}\right)$ and MPA are both high. In other words, the present is viewed as gloomy but political action is believed to be able to realise an enormous improvement. We can now consider the CMPM to ask another interesting question. What is the psychological effect of including a description of past societies in the manifesto? To answer this, let us imagine an alternative version of the manifesto with similar descriptions of $S_{\text {pres }}, S_{\text {act }}$, and $S_{\text {Noact }}$, but without any reference to $S_{\text {pre hist }}, S_{\text {Rome }}, S_{\text {mid age }}$. This alternative version would be characterised by $R\left(S_{\text {pres }}\right)=$ $R\left(S_{\text {Noact }}\right)=40$ and by $R\left(S_{\text {act }}\right)=600$. Applying Equation 1, we now obtain $V\left(S_{\text {act }}\right)=0.760, V\left(S_{\text {Noact }}\right)=0.360, V\left(S_{\text {pres }}\right)=0.360$, and $M P A=0.401$ (Figure 6b). Comparing this imaginary manifesto with the original one, the subjective value of $S_{a c t}$, $S_{\text {pres }}$ and $S_{\text {Noact }}$ all decrease. This is because the contextual average $\mu$ of the original manifesto is lower. In addition, the contextual $S D \sigma$ of the original manifesto is smaller, implying that the distance among representations increases. A consequence is that the MPA is larger in the original, compared to our imaginary, manifesto. In other words, applying the CMPM allows us to predict that including a description of past societies which are as negative as the present society has the effect of boosting the motivation for political action. This is a specific prediction of the CMPM which remains to be empirically investigated.

In short, here we have described how the CMPM can inspire empirical research relying on experimental, observational, and textual investigation. We have discussed an example of the latter by focusing on the Communist manifesto. Though textual analysis is more exposed to subjectivity, nevertheless we argue that the CMPM can be fruitfully applied to characterise interesting qualitative aspects, as the example discussed here suggests.

\section{Discussion}

A recent perspective advocates the adoption of mathematical modelling as a powerful tool to deepen our knowledge in political psychology (Fried, 2020; Rollwage et al., 2019; Zmigrod, 2020). This perspective emphasizes how computational modelling can help characterising political attitude and behaviour as manifested empirically. Building on this, here we argue that, in addition to supporting empirical research, mathematical modelling can also contribute to theoretical research in political psychology. This paper offers an example of a novel theory, grounded on simple mathematical 
modelling, about one of the central concepts in political psychology, namely the concept of political motivation. The model proposes that the subjective value of different representations of society is calculated in a reference-dependent manner and plays a key role in determining the motivation to act politically and the ensuing political mood evoked.

Our goal was to offer a simple and clear model of political motivation. This has required simplifications that might be revised in the future. First, the current version of the CMPM includes only two representations of the future ( $S_{\text {act }}$ and $S_{\text {Noact }}$ ). This is clearly a simplification, because multiple future temporal points can be conceived (e.g., the Communist manifesto distinguishes between socialist and communist society; Marx \& Engels, 1848/2002), multiple political actions can be considered (each potentially leading to a different future society), and because each action could potentially lead to multiple outcomes, each with some probability. Second, the CMPM currently does not consider the role of uncertainty. Each representation of society might be linked with some level of uncertainty. For example, there might be uncertainty about how a society worked in the past, or about how the society works now or will work in the future. Also, there might be uncertainty about the outcome of different political actions. Finally, uncertainty could be represented at different hierarchical levels (higher level uncertainty, such as about outcome probability, is often referred to as volatility; e.g., Behrens et al., 2007). Third, the CMPM assumes that each representation within the context exerts the same impact on reference effects. This might be oversimplistic. For example, it might be that the farther a representation in time, the lesser its impact on reference effects. These are all aspects currently not contemplated by the CMPM, but which deserve careful theoretical and empirical consideration by future research.

To summarise, here we propose a new perspective for interpreting political motivation, based on a simple mathematical model of referent cognition. We argue that the model can offer valuable insight and can integrate a more classical approach to the study of political motivation (Crosby, 1976; Davies, 1962; Deutsch, 1975; Doris, 2010; Folger, 1986; Gurr, 1970; Haidt, 2007; Klandermans \& van Stekelenburg, 2013; Olson, 1965; Mackie et al., 2000; Mackie \& Smith, 2002; Runciman, 1966; Smith \& Pettigrew, 2015; Stouffer et al., 1949; Tajfel, 1981; Tajfel \& Turner, 1979; Turner et al., 1987; Tyler, 2003; Van Zomeren et al., 2008). The model can potentially inspire theoretical and empirical investigation, encompassing experimental and observational studies as well as textual analysis.

Funding: The author has no funding to report.

Competing Interests: The author has declared that no competing interests exist.

Acknowledgments: I am grateful to Nicola Catenacci Volpi for comments on a previous draft of this manuscript.

\section{References}

Behrens, T. E., Woolrich, M. W., Walton, M. E., \& Rushworth, M. F. (2007). Learning the value of information in an uncertain world. Nature Neuroscience, 10, 1214-1221. https://doi.org/10.1038/nn1954

Corcoran, K. E., Pettinicchio, D., \& Young, J. T. (2011). The context of control: A cross-national investigation of the link between political institutions, efficacy, and collective action. British fournal of Social Psychology, 50, 575-605.

https://doi.org/10.1111/j.2044-8309.2011.02076.x

Crosby, F. (1976). A model of egoistical relative deprivation. Psychological Review, 83, 85-113. https://doi.org/10.1037/0033-295X.83.2.85

Dalton, R., Van Sickle, A., \& Weldon, S. (2010). The individual-institutional nexus of protest behaviour. British fournal of Political Science, 40, 51-73. https://doi.org/10.1017/S000712340999038X

Davies, J. C. (1962). Toward a theory of revolution. American Sociological Review, 27, 5-19. https://doi.org/10.2307/2089714

Dayan, P. (2012). Instrumental vigour in punishment and reward. European fournal of Neuroscience, 35, 1152-1168.

https://doi.org/10.1111/j.1460-9568.2012.08026.x

Deutsch, M. (1975). Equity, equality, and need: What determines which value will be used as the basis of distributive justice? fournal of Social Issues, 31, 137-149. https://doi.org/10.1111/j.1540-4560.1975.tb01000.x

Doris, J. M., \& the Moral Psychology Research Group. (2010). The moral psychology handbook. Oxford, United Kingdom: Oxford University Press. 
Fernando, J. W., Burden, N., Ferguson, A., O’Brien, L. V., Judge, M., \& Kashima, Y. (2018). Functions of utopia: How utopian thinking motivates societal engagement. Personality and Social Psychology Bulletin, 44, 779-792. https://doi.org/10.1177/0146167217748604

Folger, R. (1986). A referent cognitions theory of relative deprivation. In J. M. Olson, C. P. Herman, \& M. P. Zanna (Eds.), Relative deprivation and social comparison: The Ontario symposium (Vol. 4, pp. 33-55). Hillsdale, NJ, USA: Lawrence Erlbaum Associates.

Fried, E. I. (2020). Lack of theory building and testing impedes progress in the factor and network literature. PsyArXiv. https://doi.org/10.31234/osf.io/zg84s

Glimcher, P. W., \& Fehr, E. (Eds.). (2013). Neuroeconomics: Decision making and the brain. London, United Kingdom: Academic Press.

Gurr, T. R. (1970). Why men rebel. Abingdon, United Kingdom: Routledge.

Haidt, J. (2007). The new synthesis in moral psychology. Science, 316, 998-1002. https://doi.org/10.1126/science.1137651

Helson, H. (1948). Adaptation-level as a basis for a quantitative theory of frames of reference. Psychological Review, 55, 297-313. https://doi.org/10.1037/h0056721

Hobbes, T. (1998). On the citizen. Cambridge, United Kingdom: Cambridge University Press. (Original work published 1642)

Hogg, M. A. (2018). Social identity theory. In P. J. Burke (Ed.), Contemporary social psychological theories (2nd ed., pp. 112-138). Stanford, CA, USA: Stanford University Press.

Kahneman, D., \& Tversky, A. (1979). Prospect theory: An analysis of decision under risk. Econometrica, 47, 263-292. https://doi.org/10.2307/1914185

Klandermans, P. G., \& van Stekelenburg, J. (2013). Social movements and the dynamics of collective action. In L. Huddy, D. O. Sears, \& J. S. Levy (Eds.), The Oxford handbook of political psychology (2nd ed., pp. 774-812). Oxford, United Kingdom: Oxford University Press.

Lazarus, R. S. (1982). Thoughts on the relations between emotion and cognition. American Psychologist, 37, $1019-1024$. https://doi.org/10.1037/0003-066X.37.9.1019

Lazarus, R. S., \& Smith, C. A. (1988). Knowledge and appraisal in the cognition-emotion relationship. Cognition and Emotion, 2 , 281-300. https://doi.org/10.1080/02699938808412701

Louie, K., \& Glimcher, P. W. (2017). Computational principles of value coding in the brain. In J. C. Dreher \& L. Tremblay (Eds.), Decision neuroscience: An integrative perspective (pp. 121-136). London, United Kingdom: Elsevier.

Louie, K., Khaw, M. W., \& Glimcher, P. W. (2013). Normalization is a general neural mechanism for context-dependent decision making. Proceedings of the National Academy of Sciences of the United States of America, 110, 6139-6144. https://doi.org/10.1073/pnas.1217854110

Mackie, D. M., Devos, T., \& Smith, E. R. (2000). Intergroup emotions: Explaining offensive action tendencies in an intergroup context. fournal of Personality and Social Psychology, 79, 602-616. https://doi.org/10.1037/0022-3514.79.4.602

Mackie, D. M., \& Smith, E. R. (Eds.). (2002). From prejudice to intergroup emotions: Differentiated reactions to social groups. New York, NY, USA: Psychology Press.

Maier, S. F., \& Seligman, M. E. (1976). Learned helplessness: Theory and evidence. fournal of Experimental Psychology: General, 105(1), 3-46. https://doi.org/10.1037/0096-3445.105.1.3

Marx, K., \& Engels, F. (2002). The communist manifesto. New York, NY, USA: Penguin. (Original work published 1848)

Newell, B. R., Lagnado, D. A., \& Shanks, D. R. (2015). Straight choices: The psychology of decision making. Hove, United Kingdom: Psychology Press.

Oberschall, A. (1973). Social conflict and social movements. Englewood Cliffs, NJ, USA: Prentice Hall.

Olson, M. (1965). The logic of collective action: Public goods and the theory of groups. Cambridge, MA, USA: Harvard University Press.

Parducci, A. (1965). Category judgment: A range-frequency model. Psychological Review, 72, 407-418. https://doi.org/10.1037/h0022602

Pettigrew, T. F., Christ, O., Wagner, U., Meertens, R. W., Van Dick, R., \& Zick, A. (2008). Relative deprivation and intergroup prejudice. fournal of Social Issues, 64, 385-401. https://doi.org/10.1111/j.1540-4560.2008.00567.x

Rigoli, F. (2019). Reference effects on decision-making elicited by previous rewards. Cognition, 192, Article 104034. https://doi.org/10.1016/j.cognition.2019.104034

Rigoli, F., Friston, K. J., Martinelli, C., Selaković, M., Shergill, S. S., \& Dolan, R. J. (2016b). A Bayesian model of context-sensitive value attribution. eLife, 5, Article e16127. https://doi.org/10.7554/eLife.16127

Rigoli, F., Pezzulo, G., \& Dolan, R. J. (2016a). Prospective and Pavlovian mechanisms in aversive behaviour. Cognition, 146, 415-425. https://doi.org/10.1016/j.cognition.2015.10.017 
Rollwage, M., Zmigrod, L., de-Wit, L., Dolan, R. J., \& Fleming, S. M. (2019). What underlies political polarization? A manifesto for computational political psychology. Trends in Cognitive Sciences, 23, 820-822. https://doi.org/10.1016/j.tics.2019.07.006

Runciman, W. G. (1966). Relative deprivation and social justice: A study of attitudes to social inequality in twentieth-century England (Vol. 13). Berkeley, CA, USA: University of California Press.

Sassenberg, K., \& Woltin, K.-A. (2008). Group-based self-regulation: The effects of regulatory focus. European Review of Social Psychology, 19, 126-164. https://doi.org/10.1080/10463280802201894

Schacter, D. L., Addis, D. R., \& Buckner, R. L. (2007). Remembering the past to imagine the future: The prospective brain. Nature Reviews Neuroscience, 8, 657-661. https://doi.org/10.1038/nrn2213

Seligman, M. E. (1974). Depression and learned helplessness. In R. J. Friedman \& M. M. Katz (Eds.), The psychology of depression: Contemporary theory and research (pp. 83-113). New York, NY, USA: John Wiley \& Sons.

Smith, H. J., \& Pettigrew, T. F. (2015). Advances in relative deprivation theory and research. Social fustice Research, 28, 1-6. https://doi.org/10.1007/s11211-014-0231-5

Stewart, N., Chater, N., \& Brown, G. D. (2006). Decision by sampling. Cognitive Psychology, 53, 1-26. https://doi.org/10.1016/j.cogpsych.2005.10.003

Stewart, N., Reimers, S., \& Harris, A. J. (2015). On the origin of utility, weighting, and discounting functions: How they get their shapes and how to change their shapes. Management Science, 61, 687-705. https://doi.org/10.1287/mnsc.2013.1853

Stouffer, S. A., Suchman, E. A., Devinney, L. C., Star, S. A., \& Williams, R. M., Jr. (1949). The American soldier: Adjustment during army life (Studies in social psychology in World War II). Princeton, NJ, USA: Princeton University Press.

Suddendorf, T., \& Corballis, M. C. (2007). The evolution of foresight: What is mental time travel, and is it unique to humans? Behavioral and Brain Sciences, 30, 299-313. https://doi.org/10.1017/S0140525X07001975

Tajfel, H. (1981). Human groups and social categories: Studies in social psychology. Cambridge, United Kingdom: Cambridge University Press.

Tajfel, H., \& Turner, J. C. (1979). An integrative theory of intergroup conflict. In W. G. Austin \& S. Worchel (Eds.), The social psychology of intergroup relations (pp. 33-37). Monterey, CA, USA: Brooks/Cole.

Turner, J. C., Hogg, M. A., Oakes, P. J., Reicher, S. D., \& Wetherell, M. S. (1987). Rediscovering the social group: A self-categorization theory. Oxford, United Kingdom: Basil Blackwell.

Tyler, T. R. (2003). Social justice. In R. Brown \& S. L. Gaertner (Eds.), Blackwell handbook of social psychology: Intergroup processes (pp. 344-364). Malden, MA, USA: Wiley.

Van Zomeren, M., Postmes, T., \& Spears, R. (2008). Toward an integrative social identity model of collective action: A quantitative research synthesis of three socio-psychological perspectives. Psychological Bulletin, 134, 504-535. https://doi.org/10.1037/0033-2909.134.4.504

Van Zomeren, M., Spears, R., Fischer, A. H., \& Leach, C. W. (2004). Put your money where your mouth is! Explaining collective action tendencies through group-based anger and group efficacy. Journal of Personality and Social Psychology, 87, 649-664. https://doi.org/10.1037/0022-3514.87.5.649

Zmigrod, L. (2020). The role of cognitive rigidity in political ideologies: Theory, evidence, and future directions. Current Opinion in Behavioral Sciences, 34, 34-39. https://doi.org/10.1016/j.cobeha.2019.10.016 